\title{
EDITORIAL
}

\section{Is the literature inconclusive about the harm of HES? We are not sure}

\author{
Miet Schetz $^{1 *}$ (D, Andrew D. Shaw ${ }^{2}$ and Jean-Louis Vincent ${ }^{3}$
}

Intravenous hydroxyethyl starch (HES) solutions were introduced for clinical use about 50 years ago without extensive clinical assessment, and this is also the case for the other currently available IV fluid solutions. HES solutions found widespread acceptance because, when compared with crystalloids, their use is associated with a superior volume effect resulting in faster hemodynamic stability with less total volume, and thus a less-positive fluid balance [1]. Experimental data also showed positive effects on the microcirculation and attenuated inflammation. In addition, starch solutions are cheaper than albumin and they have longer shelf lives. Small studies with older HES molecules suggested renal toxicity, impaired coagulation, and long-term retention in the reticuloendothelial system [2]. The nephrotoxicity has been related to their storage in tubular cells (osmotic nephrosis) [3]. The modern tetrastarches were supposed to be devoid of these toxic side effects because of their lower average molecular weight, degree of substitution, and concentration. Recent trials have challenged this assumption, however.

The $6 \mathrm{~S}$ trial in 800 patients with severe sepsis and high illness severity (control group mortality $43 \%$ ) showed increased 90-day mortality, increased need for renal replacement therapy (RRT), and increased requirement for blood products in the HES group [4]. This trial compared a more recently developed potato-based isotonic tetrastarch molecule dissolved in a balanced carrier fluid versus a buffered crystalloid solution in the control group. In contrast to traditional expectations of a need

\footnotetext{
*Correspondence: miet.schetz@scarlet.be

${ }^{1}$ Division of Cellular and Molecular Medicine, Clinical Department and Laboratory of Intensive Care Medicine, KU Leuven University, Herestraat 49, 3000 Louvain, Belgium

Full author information is available at the end of the article

Contrasting viewpoints can be found at doi:10.1007/s00134-016-4275-x and doi:10.1007/s00134-016-4278-7.
}

for more crystalloid, there was no significant difference in the cumulative volume of resuscitation fluid used, in hemodynamic parameters in the first $24 \mathrm{~h}$, or in fluid balance over the first three study days.

In the CHEST trial, 7000 ICU patients who were less sick (control group mortality $17 \%$ ) but who had a requirement for fluid resuscitation were randomized to a saline-based maize-derived isotonic tetrastarch or $0.9 \%$ saline, prepared in indistinguishable bags [5]. This study did not show a difference in 90-day mortality, but reported an increased need for renal replacement therapy, somewhat higher creatinine levels, and increased need for blood products in the HES group. However, the CHEST results were not entirely internally consistent with a hazard attributable to HES. First, the trial showed a greater volume effect of HES than saline. Indeed, the HES patients had higher mean central venous pressures (perhaps reflecting greater intravascular persistence) and a significantly lower incidence of new cardiovascular failure. This occurred in the presence of a substantially lower amount of study fluid, and together with the higher urine output, this in turn resulted in a less positive fluid balance in the HES group. Second, fewer patients in the HES group experienced mild or moderate acute kidney injury (AKI) (by RIFLE criteria) than in the saline group. This observation was confirmed in a Cochrane analysis (based on 8769 patients in 20 studies) and might be related to the better short-term volume effect reversing a prerenal state, whereas more severe forms of AKI could be the result of tissue accumulation of starch leading to injury in susceptible kidneys. It is also possible that a mild diuretic effect was present in those healthier patients, reducing the incidence of oliguria and thus of mild AKI. After deletion of the urine output criteria for AKI, the difference for the milder forms disappeared and the association with more severe forms strengthened [6].

When considered together, the $6 \mathrm{~S}$ and CHEST trials appear to suggest that worse survival is only shown

\section{Springer}


in patients with severe sepsis and high illness severity, although this idea was not specifically reported in either study alone $[4,5]$. Whether this represents a true dose effect or an increased susceptibility to starch toxicity in severely ill patients is not clear [7]. Mainly on the basis of these two trials, regulatory agencies around the world made it either impossible or very difficult to use HES solutions in critically ill patients, and demanded restrictions and renal follow-up in other settings. The resulting controversy resulted in a proliferation of meta-analyses and heavy debates $[8,9]$. This debate has recently intensified with the publication of a report which appears to demonstrate inconsistencies in the adverse event (AE) reporting methodology of the CHEST trial [10]. Specifically, it is unclear whether or not all patients exposed to HES prior to randomization were included in the HES group, or just those who subsequently experienced an AE. Although this controversy will probably not change the principal findings of the study, and thus arguably will not affect the regulators' positions either, there appears to be a need to clarify precisely which patients did and did not experience an AE.

Limitations of the $6 \mathrm{~S}$ and CHEST trials included the absence of significant differences in AKI incidence, the lack of predefined indications for the initiation of RRT, the absence of an effect on RRT after adjustment for confounders in CHEST, prolonged administration of study fluids, protocol violations, not respecting dose limitations, and doubts about the appropriateness and effectiveness of fluid resuscitation in patients that were already fluid-resuscitated before inclusion [11, 12]. Unnecessary fluid-induced hypervolemia could have stimulated the release of atrial natriuretic peptide (ANP) that in turn caused shedding of the glycocalyx, potentially explaining the absence of a differential volume effect [13].

The key question is whether these findings are relevant also to the short-term use of starch solutions, e.g., in the operating room environment, and whether or not they apply to the initial hemodynamic stabilization of acutely hypovolemic patients. Another randomized trial of colloids versus crystalloids in the ICU setting (CRISTAL trial) found no difference in 28-day mortality or need for RRT. There were also fewer days of mechanical ventilation and cardiovascular support with colloids (mainly starches) when compared with crystalloids. In fact, patients treated with colloids in that study had better 90-day survival [14]. As expected, the median volume administered in the first 7 days was significantly higher in the crystalloid group. Faster hemodynamic stabilization with HES had also been previously reported in the CRYSTMAS trial [15].
Other settings of acute hypovolemia include trauma and surgery, both situations with a lower risk of glycocalyx disruption. In the setting of penetrating trauma a blinded comparison of tetrastarch with $0.9 \%$ saline demonstrated that the colloid group received less fluid, had a more rapid decrease in lactate, and less renal injury. In blunt trauma no difference in fluid requirement was noted but the HES group required more blood products [16]. In high-risk surgical patients, goal-directed therapy including starches for preload optimization has been shown to reduce postoperative complications. Two small, blinded randomized controlled studies (RCTs) in this setting found a volumesparing effect with tetrastarches compared with crystalloids without adverse renal outcomes, although the event rate for the latter was very low $[17,18]$.

Most studies comparing starches with other fluids in surgical patients are small, non-blinded, and have low event rates and short follow-up [19, 20]. In contrast to the short-term benefit related to the volume-sparing and improved volume effect with faster hemodynamic stabilization, the potential harm from starches may require more time to manifest: "immediate gratification with delayed costs" [7]. In this regard it is interesting to note that the mortality curves in the $6 \mathrm{~S}$ trial only started to diverge after 15-20 days. Alternatively the short-term advantages may have long-term benefit that outweighs harm in surgical patients [7]. However the available evidence does not allow a definitive conclusion.

In summary, outside the ICU harm from correcting acute hypovolemia with starches has not been clearly demonstrated, but we still lack adequately designed RCTs. The evidence of benefit is limited to short-term effects on hemodynamics and fluid balance. This knowledge gap could potentially be filled with large blinded randomized trials evaluating long-term outcomes with regard to survival and morbidity, including kidney function. While awaiting these results clinicians should consider fluids as IV drugs that should be used with the same caution and respect as any other medication, taking into account the specific indication for their use, any contraindications, and with careful consideration of the possibility of toxicity.

\footnotetext{
Author details

${ }^{1}$ Division of Cellular and Molecular Medicine, Clinical Department and Laboratory of Intensive Care Medicine, KU Leuven University, Herestraat 49, 3000 Louvain, Belgium. ${ }^{2}$ Department of Anesthesiology, Vanderbilt University Medical Center, Nashville, TN, USA. ${ }^{3}$ Department of Intensive Care, Erasme Hospital, Université Libre de Bruxelles, Brussels, Belgium.
}

Compliance with ethical standards

Conflicts of interest

No conflicts of interest. 
Received: 11 March 2016 Accepted: 11 March 2016

Published online: 23 March 2016

\section{References}

1. Cortés DO, Barros TG, Njimi H, Vincent JL (2015) Crystalloids versus colloids: exploring differences in fluid requirements by systematic review and meta-regression. Anesth Analg 120:389-402

2. Wiedermann CJ (2004) Hydroxyethyl starch — can the safety problems be ignored? Wien Klin Wochenschr 116:583-594

3. Wiedermann CJ, Joannidis M (2014) Accumulation of hydroxyethyl starch in human and animal tissues: a systematic review. Intensive Care Med 40:160-170

4. Perner A, Haase N, Guttormsen AB, Tenhunen J, Klemenzson G, Åneman A, Madsen KR, Møller MH, Elkjær JM, Poulsen LM, Bendtsen A, Winding R Steensen M, Berezowicz P, Søe-Jensen P, Bestle M, Strand K, Wiis J, White JO, Thornberg KJ, Quist L, Nielsen J, Andersen LH, Holst LB, Thormar K, Kjældgaard AL, Fabritius ML, Mondrup F, Pott FC, Møller TP, Winkel P, Wetterslev J, 6S Trial Group, Scandinavian Critical Care Trials Group (2012) Hydroxyethyl starch 130/0.42 versus Ringer's acetate in severe sepsis. N Engl J Med 367:124-134

5. Myburgh JA, Finfer S, Bellomo R, Billot L, Cass A, Gattas D, Glass P, Lipman J, Liu B, McArthur C, McGuinness S, Rajbhandari D, Taylor CB, Webb SA CHEST Investigators, Australian and New Zealand Intensive Care Society Clinical Trials Group (2012) Hydroxyethyl starch or saline for fluid resuscitation in intensive care. N Engl J Med 367:1901-1911

6. Mutter TC, Ruth CA, Dart AB (2013) Hydroxyethyl starch (HES) versus other fluid therapies: effects on kidney function. Cochrane Database Syst Rev 7:CD007594

7. Shaw AD, Kellum JA (2013) The risk of AKI in patients treated with intravenous solutions containing hydroxyethyl starch. Clin J Am Soc Nephrol 8:497-550

8. Bion J, Bellomo R, Myburgh J, Perner A, Reinhart K, Finfer S (2014) Hydroxyethyl starch: putting patient safety first. Intensive Care Med 40:256-259

9. Meybohm P, Van Aken H, De Gasperi A, De Hert S, Della Rocca G, Girbes AR, Gombotz H, Guidet B, Hasibeder W, Hollmann MW, Ince C, Jacob M, Kranke P, Kozek-Langenecker S, Loer SA, Martin C, Siegemund M, Wunder C, Zacharowski K (2013) Re-evaluating currently available data and suggestions for planning randomised controlled studies regarding the use of hydroxyethyl starch in critically ill patients - a multidisciplinary statement. Crit Care 17:R166

10. Doshi P (2016) Data too important to share: do those who control the data control the message? BMJ 352:11027
11. De Hert S, De Baerdemaeker L (2014) Why hydroxyethyl starch solutions should NOT be banned from the operating room. Anaesthesiol Intensiv Ther 46:336-341

12. Irwin MG, Gan TJ (2014) Volume therapy with hydroxyethyl starches: are we throwing the anesthesia baby out with the intensive care unit bathwater? Anesth Analg 119:737-739

13. Chappell D, Bruegger D, Potzel J, Jacob M, Brettner F, Vogeser M, Conzen P, Becker BF, Rehm M (2014) Hypervolemia increases release of atrial natriuretic peptide and shedding of the endothelial glycocalyx. Crit Care 18:538

14. Annane D, Siami S, Jaber S, Martin C, Elatrous S, Declère AD, Preiser JC, Outin H, Troché G, Charpentier C, Trouillet JL, Kimmoun A, Forceville X, Darmon M, Lesur O, Reignier J, Abroug F, Berger P, Clec'h C, Cousson J, Thibault L, Chevret S, CRISTAL Investigators (2013) Effects of fluid resuscitation with colloids vs crystalloids on mortality in critically ill patients presenting with hypovolemic shock: the CRISTAL randomized trial. JAMA 310:1809-1817

15. Guidet B, Martinet O, Boulain T, Philippart F, Poussel JF, Maizel J, Forceville X, Feissel M, Hasselmann M, Heininger A, Van Aken H (2012) Assessment of hemodynamic efficacy and safety of $6 \%$ hydroxyethylstarch 130/0.4 vs. $0.9 \% \mathrm{NaCl}$ fluid replacement in patients with severe sepsis: the CRYSTMAS study. Crit Care 16:R94

16. James MF, Michell WL, Joubert IA, Nicol AJ, Navsaria PH, Gillespie RS (2011) Resuscitation with hydroxyethyl starch improves renal function and lactate clearance in penetrating trauma in a randomized controlled study: the FIRST trial (fluids in resuscitation of severe trauma). $\mathrm{Br}$ J Anaesth 107:693-702

17. Yates DR, Davies SJ, Milner HE, Wilson RJ (2014) Crystalloid or colloid for goal-directed fluid therapy in colorectal surgery. Br J Anaesth 112:281-289

18. Feldheiser A, Pavlova V, Bonomo T, Jones A, Fotopoulou C, Sehouli J, Wernecke KD, Spies C (2013) Balanced crystalloid compared with balanced colloid solution using a goal-directed haemodynamic algorithm. $\mathrm{Br}$ J Anaesth 110:231-240

19. Martin C, Jacob M, Vicaut E, Guidet B, Van Aken H, Kurz A (2013) Effect of waxy maize-derived hydroxyethyl starch 130/0.4 on renal function in surgical patients. Anesthesiology 118:387-394

20. Gillies MA, Habicher M, Jhanji S, Sander M, Mythen M, Hamilton M, Pearse RM (2014) Incidence of postoperative death and acute kidney injury associated with i.v. $6 \%$ hydroxyethyl starch use: systematic review and meta-analysis. Br J Anaesth 112:25-34 